\section{The Virtual, The Actual, and The Aspen Idea}

\author{
Amir Alrubaiy \\ University of Colorado Denver
}

\section{INTRODUCTION}

This paper expresses a challenge to the problematic conceptual division between teaching and practice in architecture. This division generates a troublesome tension between the university and the profession as it maintains a condition of perpetual reconciliation between the two. This challenge is issued through an account of the Aspen Summer Design Program at the University of Colorado Denver College of Architecture and Planning, taught in conjunction with Harry Teague Architects, CCY Architects, and Studio B Architects in Colorado's Roaring Fork Valley. Through a reading of the concept of the Virtual and the Actual as articulated primarily by Henri Bergson and Gilles Deleuze ${ }^{1}$, and a connection of these concepts to ideas of situatedness and embodiment implicit in the Aspen Idea of Albert Schweitzer, the Summer Design Program demonstrates a manifestation of a more overlapping and simultaneous conception of teaching and practice.

\section{CASE}

Common discourse around the relationship between teaching and practice tends to center either on the proper influence one ought to have over the other, or the mechanism by which the knowledge developed in one transfers to the other. This is a result of the two areas being conceived in opposition to one another; defined in negation. Our word "practice" derives from the Greek "Prakitos" and its feminine "Prakité." Both words meaning something like "of action." Activity connotes a condition of movement and is therefore spatial and embodied. In order for a thing to move, there must be a medium through which it moves. When we speak of teaching/practice as a pair, or as distinct "things" we implicitly define each as the opposite of the other. If "practice" is action, then "teaching" become the opposite of action. It is defined as in-action, and by extension dis-embodied.

This binary arrangement, while convenient and useful to the degree that it allows operations in each area to occur with a sense of suspended stability, also generates unproductive isolation and dissociation within each zone. In the architect's office, the difficulties of conceptual rigor can be dismissed as merely "academic," and in the studio, the consequences of building may be put off as overly "practical." Teaching and practice generate barriers across which they generate mutual opposition. It becomes necessary to construct connections between that which was never really apart. Rather than continuing to reconcile these unnecessarily discreet modes of architecture, the Aspen Summer Program, and the framework in which it is situated, arrange teaching and practice along a continuum. This continuum is a virtuality, of which "teaching" and "practice" are merely different actualizations.

\section{THE VIRTUAL AND THE ACTUAL}

The first question we may ask is, how does a concept of the virtual and the actual help recalibrate our approaches to teaching and practice? In order to answer this question, it is necessary to examine some of the original thinking done around ideas of virtuality and actuality as articulated by Henri Bergson, and later Gilles Deleuze. 
Bergson was a French-Jewish philosopher who lived from 18591941. He is notable for his work expounding a philosophy of intuition and experience as primary (or at least co-incident) to science and rationality. He was deeply suspicious of the dominance of positivistic and analytical approaches emerging in philosophy at the time, as well as the infiltration of an overly scientific paradigm applied to descriptions of human existence and experience.

Bergson's primary contribution to philosophy was his concept of "duration." 2 This is a theory of space and time that asserts that what we commonly think of as enduring temporally is actually persisting spatially. In other words, that we measure time spatially. When we perceive a thing changing or not, we register that change relative to a position or extension in space. "Every clear idea of a number implies a visual image in space." ${ }^{\prime \prime}$ In this way, change over time becomes change in space. Time and space are interwoven and time becomes implicitly spatial. This conception suggests a cosmology where things are either multiple and in time/space, or unified and a-temporal and non-spatial.

Bergson's concept of duration is a way around this choice. For him, duration is expressive of the condition of human life and memory. "When we add the present moment those which have preceded it... we are not dealing with these moments themselves, since they have vanished forever, but with the lasting traces which they seem to have left in space on their passage through it."4 Neither fixed nor complete. Neither completely unified nor absolutely multiple; neither ideal nor real. Duration is ephemeral and mobile, and critical for the purposes of this discussion, incapable of being grasped by immobile ideas.

Gilles Deleuze, the French post-structuralist and materialist philosopher, spends a lot of time digging into and extending these ideas. He dedicates one of his books to an exposition of his Bergsonism, ${ }^{5}$ and the foundations of much of his thinking on difference and the virtual and actual, can be traced to Bergson's work.

Deleuze, while commonly read among architects for his descriptions of flows and gradients, as well as his use of the rhizomatic metaphor to describe ordered but non-original systems, is notable in philosophy for his recalibration of the point of philosophy. In their 1991 work What is Philosophy?, 6 Deleuze and his longtime collaborator Felix Guattari...well, they do a number of things. The most significant for the purposes of this story, is their reformulation of the role of philosophy as being about the discovery of truth, and instead, the production of concepts.

As post-structuralists, they accept the proposition of the impossibility of ultimate truth, or at least a knowable and un-contingent truth. But rather than use this position as a rationale for throwing out the value of thousands of years of philosophical work, they assert that instead of working to discover truth(s), philosophy is a creative act that embodies the conceptual grappling thinkers do with the world they find themselves situated in. In this way, philosophy need not be dismissed as a fruitless pursuit, but instead, philosophical work manifests as a succession of more or less productive ways of conceiving the world. These conceptions, rather than aspiring to describe the world with greater fidelity, instead operate as a framework with which to engage the specific situations and contexts from which they emerge. These frameworks are valued based on their ability to provide productive and useful ways of engaging these situations. This situatedness is a condition integral to the operation of the Virtual and the Actual.

So, what do Bergson, and later Deleuze mean by these concepts? In their description, the virtual is something like potential or possible. But unlike these ideas, the virtual is situated and real. We can imagine a possible world where I am a chicken, or a tree, but those possibilities do not align with the situatedness the world. The virtual remains immanent and unrealized, but is at the same time, materialized in the sense that it is subject to the conditions that give rise to it.

A more useful analogy for the virtual is that of a battery. It stores potential energy. That energy, in this example, conforms to the physical constraints that electrical-chemical reactions demand. This battery may power a light bulb or a child's astonishingly loud toys. It may not work at all for any number of reasons. It may be forgotten and lost. The conditions of the virtual are inflected by the actualizations it may produce. Additionally, if we remember Bergson's ideas about time, the virtual is ephemeral and simultaneously definitive of and defined by those things actualized through it. It both forms and is formed by the things it gives rise to.

The Actual, by contrast, although we're warry of such things here, is defined by its fixedness and ability to be known. The Virtual may be approached only obliquely; though intuition in regarding the future, and though memory in relation to the past. As Deleuze states at the end of his essay on the subject, "Actuals imply already constituted individuals, and are ordinarily determined." " The actual occupies time and diminishes with its passing. Where the Virtual endures, the actual dissipates. The Actual is the ever diminishing, embodied now. Again Deleuze; "The actual is defined by the passing of the present."

The relationship between virtuality and actuality, then, is not characterized in terms of the priority one takes over the other, but instead, the mutually productive condition their interaction produces. For Deleuze, the virtual and the actual exist as if along a circuit; more accurately a nest of overlapping and interconnected circuits. This arrangement places the Virtual and Actual into a generative network that, independent of each elements actuality, is absolutely real. This realness is equivalent to saying that they are both situated in material.

When these ideas are transferred to our understanding of teaching and practice, we can start to conceive of these undertakings less as competing modes through which architecture is more or less accurately represented and more as different ways in which architecture is actualized.

\section{THE ASPEN IDEA}

For all of its opulent reputation, Aspen's origins are as a dilapidated mining town that almost ceased to exist. If not for frozen pipes in the Chicago industrialist Walter Pepke's Denver home, Aspen would certainly not be what we imagine it to be today. But, once discovered, the Pepkes encouraged their University of Chicago friends to make annual pilgrimages there to discuss ideas, generate their concepts of an emerging American idealism and continuum across industry and culture. As these gatherings gained regularity and import, they became 
the foundation of what is now known as the Aspen institute.

Attracted to Aspen on his only U.S. visit, the French-German philosopher Albert Schweitzer articulated what came to be known as the Aspen Idea. Schweitzer's philosophy is characterized by his support of the mystical and irrational as ways of existing and engaging the world. "We know the universe by intuition, not by reason. Our life knows the life in the world, and through our life we become one with the life of the universe."

Schwweitzer's Aspen Idea extends this support for multiple actualizations of human existance through an ethic of philosophical life organized around the cultivation of a vital body, a curious mind, and a striving spirit. In the idea's emergence, the high alpine isolation of Aspen served as context in which this triadic ethic is initially situated. What is notable about the formulation of the idea is that body, mind, and spirt are not cultivated in isolation. None are treated as an autonomous personal pursuit. Instead they are conjoined and blended to the degree that the delineations among them manifest as blurry and porous rather than distinct and durable. Mind is embodied. Bodies are mindful. Spirit is situated.

Deleuze, Bergson, and Schweitzer would likely not overlap on a lot, but for the purposes of this analysis, it is useful to overlay Deleuzian materialism with Schweitzer's embodied mysticism. This overlay produces alignments that facilitate a reading of the Aspen Summer Program that challenges the rational dis-embodied opposition of teaching and practice. This occurs as the creative aspects of Deleuze's formulation of philosophy align with Schweitzer's propositions for an embodied spiritual life. In both senses, the world is made in an ever diminishing present, inflected with the influence of the fading past and immanent future.

\section{THE SUMMER DESIGN PROGRAM}

None of this would be anything beyond merely interesting if it weren't the case that the Aspen Idea is actually a living operating ethic among many people living and working in Aspen's Roaring Fork Valley. In the words of John Cottle, partner at CCY Architects, one of the program's core firms, "It wasn't a marketing gimmick, it was about how we can get better." This ethic enfolds and animates the work of these architects, and its influence is critical to the experience of the course. The Aspen Summer Program is a three week intensive design experience that embeds students within local design offices, as well as in the landscape and community, of the Roaring Fork Valley. Students live in a dense and cloistered setting that blurs the distinction between living and learning, work and play. The bulk of their design work is performed in the extra desks and conference rooms of the host offices. The nature of immersive environment, the dense living and the embeddedness in offices, is critical to the experience of the course. These qualities are distinct from other immersive programs like Ghost Lab, Rural Studio, or Immersion, which either don't have the same professional connection or extend over a longer period of time. The Aspen Summer Program is unique in its spatial, temporal, and situational compression. Indeed, it is these compressions that help to decompose the distinctions between teaching and practice.
For nearly all of the students, entering into this context is an abrupt change from the pace and setting of The University of Colorado Denver's urban campus. The shift awakens their situational awareness and sets them in a state of acute attention. As they spend each week in a different firm, engaged in an accelerated charrette project, they fold into the daily and weekly rhythm of each office and the community. They absorb the approaches and outlook of their hosts and teachers. The office setting leaves an impression on the work that is not fully professional, but no longer purely academic either. In the terms of Bergsonian duration, the situatedness of the students in the professional offices endures in the work.

In a similar way, when the projects accumulate in sequence, the "lasting traces" of the preceding work extends into the students' present pre-occupations. This rapid succession allows students to embody lessons from one week and immediately actualize them the next. Particularly in the second week, the memory of week one and the anticipation of week three haunt the development of the project.

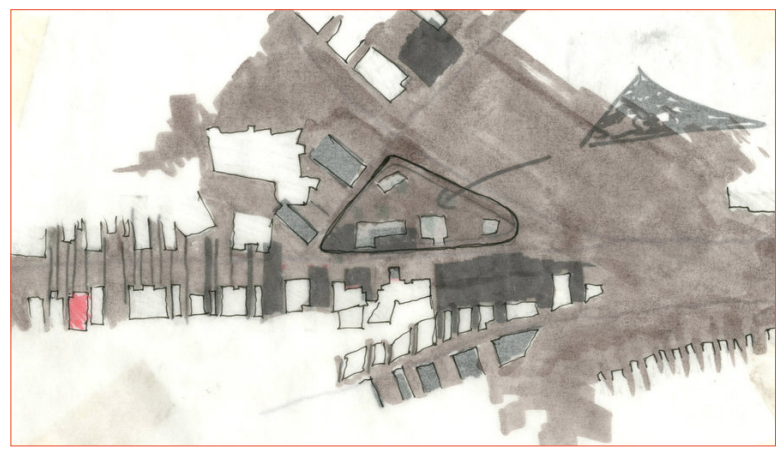

Figure 1. Site interpretation drawing.

Finally, these charrettes strategically limit students to analog media like graphite, charcoal, and ink. The process requires that they document and express subjects and conditions not immediately contextual, but intimately situational to the architecture; the sound of a river, wind in the trees. These qualities are immediately apparent, but often elusively picturable. Students must exploit the qualities and limitations of their tools to approach their subjects obliquely and liminally. These constraints and techniques facilitate a direct and personal connection between observation and reaction. There is no technological veneer in which to wrap impressions and expressions, and students must grapple with inevitable gaps in their translations. Intentions actualize directly in graphite and charcoal. Students' work is an extension of their affected senses, and most importantly generated in and from their situatedness in place and project. The best work and breakthroughs occur when students stop seeing their drawings (and projectsas an act of representation (discoveryand start treating them as an act of expression (creation 
Students evaluate their work not in terms of its resemblance to professional work, but in terms of how productive it is as an act of architectural creation.

The generative role the practitioners take in this program is also integral to its results. They lead the development and delivery of each project and are the primary instructors for the duration of the course. Their teaching is honest and without the sometimes impenetrable polish of a practiced academic presence. As they enfold the students into their approaches and observations, they gaze into a critical mirror that exposes both the blind spots and insights in their own practices. Again, John Cottle; "We do this selfishly. Teaching makes us better architects... and that makes our lives better." It is the Aspen Idea immanently manifest.

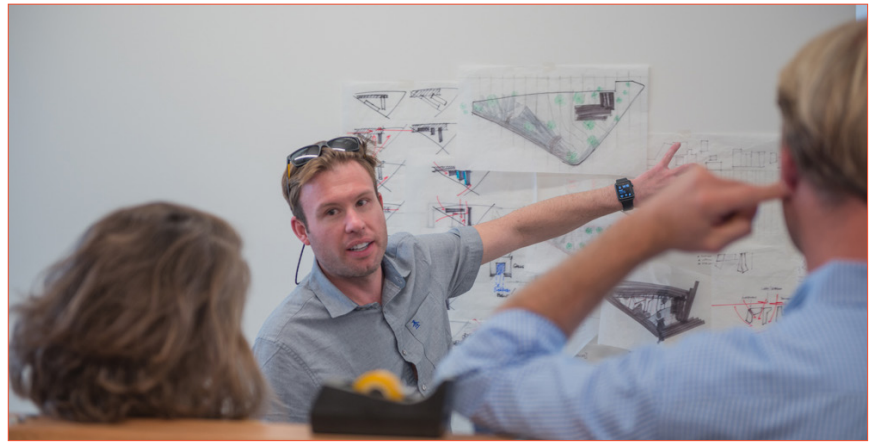

Figure 2. Project presentations.

In the course of the program, these practitioners articulate positions and processes that have gone unspoken in their offices for long periods of time. The teaching and learning roles begin to blur and invert as the lessons become reflective and reflexive. Teaching and practice reorganize across a continuum that allows both to be productive actualizations of an animating curiosity. Architectural embodiments are actualized in the teaching of the practitioners as the expedience of practice recedes virtually.

The projects are organized around actual, local proposals and pressures...an arts center, market space, a visitor's center, a hiker's overlook. They are down the street or up the hill. This proximity and tactility leaves traces of immediacy on the work. Everyone is in the project

However this proximity is held on tension with the radically exploratory ethos of the charrette. This process has been operationalized to a remarkable degree by CCY Architects. Rather than treating the charrette as an infrequent luxury, the firm employs the intensive process to all projects that come through the office. Through what they term as a process of "interviewing" the site, client, and program, they exploit the tension between the potential of a project and its' situational boundaries. This tension allows CCY's work to occupy a terrain common to both academic and practical work. In the course of the program, CCY's architects serve as guides to the students in this pervasive yet subliminal space between teaching and practice.

Through the intense and intimate working relationships between educators, professionals, and students, delineations between roles and expertise begin to blur. As the professor in the room, I find myself teaching a project I didn't develop and embodying the intentions of a practice that is not my own. My role as the lead faculty is primarily to facilitate and to help students see how their academic experience translates into a professional setting. The teaching is less about building skills and competencies than it is about showing students how much they already know.

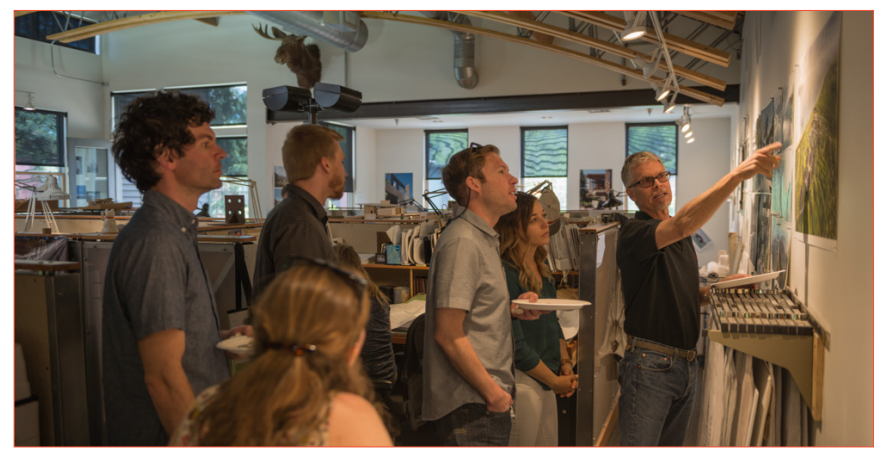

Figure 3. Daily life.

As the professionals teach projects with innocence and genuine curiosity, unencumbered by curricular sequencing and pedagogical agendas, they actualize the potential of the university. As academics operate outside of the classroom and studio, teaching materializes in practical, immediate, and applied ways uncommon to the sometimes heady isolation of the school.

The students mirror and emulate both, and in their activities a novel actual is brought forth...not quite academic...not yet practical. The origins of ideas, whether professional or academic, recede and critical development flows freely between the projects and the practice. Questions about whether work is more or less academic or professional become irrelevant. Rather than asking how should one do architecture, we explore how might one do architecture. ${ }^{10}$

\section{CONCLUSIONS}

As the flows of information begin to enfold and reverse, practitioners expose their habituated perceptions of their home to the innocent questioning of the students and students begin to show long tenured practitioners their process back to them. Throughout the course, teaching is embodied in the practice, and practice is cultivated in teaching. The rural alpine setting and tactile analog media situate students in the personal and embodied nature of their perceptions and expressions. Bodies are vital. The practitioners articulate and examine their processes and assumptions through the pragmatic filter of having to teach their ideas. Minds are cultivated. Each of these events occur around the ever receding spirit of actualizing architecture.

By reconstructing the terrain across which teaching and practice actualize, a shift occurs in our understanding of the nature of the production of architectural knowledge. Students and practitioners begin 
to remove some of the conventional divisions that typical conversations about teaching and practice assume. Instead of treating either practice or teaching as the more or less accurate or appropriate way in which an ideal architecture is brought forth, they are considered as different actualizations of how an architecture may be conceived or produced.

\section{Notes}

1. Deleuze, Gilles, and Claire Parnet. Dialogues. Paris: Flammarion, 2008.

2. Pearson, Keith Ansell, and Melissa McMahon. Henri Bergson: Key Writings. London: Bloomsbury USA Academic, 2014.

3. Ibid, p 61

4. Ibid

5. Deleuze, Gilles, Barbara Habberjam, and Hugh Tomlinson. Bergsonism. New York: Zone Books, 1991.

6. Deleuze, Gilles, and Félix Guattari. What Is Philosophy? New York: Columbia University Press, 1994.

7. Deleuze, Gilles, and Claire Parnet. "The Actual and the Virtual." In Dialogues, p 152. Paris: Flammarion, 2008.

8. Ibid, p 151

9. Schweitzer, Albert, and Charles Rhind Joy. Albert Schweitzer: And Anthology. Loc 2992 New York: Harper \& Brothers, 1947.

10. For and extended description of the transition from "how should one live" to "how might one live", see May, Todd. Gilles Deleuze: An Introduction. Cambridge: Cambridge University Press, 2006. 